\title{
Quality improvement of delirium status communication and documentation for intensive care unit patients during daily multidisciplinary rounds
}

\author{
Krishna Aparanji, ${ }^{1}$ Shreedhar Kulkarni, ${ }^{2}$ Megan Metzke, ${ }^{3}$ Yvonne Schmudde, ${ }^{4}$ \\ Peter White, ${ }^{2}$ Cassie Jaeger ${ }^{5}$
}

To cite: Aparanji K, Kulkarni S, Metzke M, et al. Quality improvement of delirium status communication and documentation for intensive care unit patients during daily multidisciplinary rounds.BMJ Open Quality 2018;7:e00239. doi:10.1136/ bmjoq-2017-000239

Received 26 0ctober 2017 Revised 23 May 2018 Accepted 7 June 2018

\section{Check for updates}

C Author(s) (or their employer(s)) 2018. Re-use permitted under CC BY-NC. No commercial re-use. See rights and permissions. Published by BMJ.

${ }^{1}$ Department of Critical Care Medicine, Springfield Clinic, Springfield, Illinois, USA ${ }^{2}$ Department of Internal Medicine, Southern Illinois University School of Medicine, Springfield, Illinois, USA ${ }^{3}$ Department of Pharmacy, Memorial Health System, Springfield, Illinois, USA ${ }^{4}$ Department of Nursing Administration, Memorial Health System, Springfield, Illinois, USA ${ }^{5}$ Department of Operations Improvement, Memorial Health System, Springfield, Illinois, USA

Correspondence to

Dr Cassie Jaeger;

Hawk.Cassie@mhsil.com

\section{ABSTRACT}

Delirium is a key quality metric identified by The Society of Critical Care Medicine for intensive care unit (ICU) patients. If not recognised early, delirium can lead to increased length of stay, hospital and societal costs, ventilator days and risk of mortality. Clinical practice guidelines recommend ICU patients be assessed for delirium at least once per shift. An initial audit at our urban tertiary care hospital in Illinois, USA determined that delirium assessments were only being performed $31 \%$ of the time. Nurses completed simulation based education and were trained using delirium screening videos. After the educational sessions, delirium documentation increased from $40 \%(12 / 30)$ to $69 \%$ (41/59) (two-proportion test, $\mathrm{p}<0.01)$ for dayshift nurses and from $27 \%(8 / 30)$ to $61 \%$ (36/59) (two-proportion test, $p<0.01$ ) during the nightshift. To further increase the frequency of delirium assessments the delirium screening tool was standardised and a critical care progress note was implemented that included a section on delirium status, management strategy and discussion on rounds. After the documentation changes were implemented, delirium screening during dayshift increased to 93\% (75/81) (two-proportion test, $p<0.01$ ). Prior to this project, physicians were not required to document delirium screening. After the standardised critical care note was implemented, documentation by physicians was 95\% (106/111). Standardising delirium documentation, communication of delirium status on rounds, in addition to education, improved delirium screening compliance for ICU patients.

\section{PROBLEM}

Clinical practice guidelines recommend intensive care unit (ICU) patients be assessed for delirium at least once per shift. ${ }^{1}$ An initial audit determined that delirium assessments for ICU patients were only being performed $31 \%$ of the time at an urban tertiary care hospital in Illinois, USA. In addition, variability existed in the assessment, documentation and interventions for ICU patients with delirium. Timely recognition and management is essential to reduce the incidence, severity and duration of delirium. To help improve patient outcomes, The Society of
Critical Care Medicine initiated an ICU Liberation Campaign to implement the ABCDEF bundle, a standardised plan that targets delirium as a key quality metric. ${ }^{2}$

\section{BACKGROUND}

Delirium, an acute state of confusion that includes symptoms of alternating mental status, inattention, disorganised thinking and/or altered consciousness, can occur in up to $80 \%$ of mechanically ventilated critically ill adult patients and up to $50 \%$ of critically ill adult patients not requiring mechanical ventilation in the ICU. ${ }^{3-5}$ Classified based on the patient's psychomotor behaviour, symptoms of delirium can be hyperactive characterised by restlessness, agitation and delusions or hypoactive characterised by lethargy and slow response time. A combination of hyperactive and hypoactive symptoms is described as mixed delirium. ${ }^{6}$ Identification of hypoactive delirium, which comprises around $44 \%$ of delirium cases, can be difficult because patients may appear calm and relaxed. ${ }^{7}$

Delirium is associated with increased hospital and ICU stay. ${ }^{45}$ Ely et al, reported that ICU patients with delirium spend an average 10 days longer in the hospital than ICU patients without delirium. ${ }^{4}$ Delirium is also associated with a higher incidence of cognitive impairment at hospital discharge and higher hospital and ICU mortality. ${ }^{489}$ The cost of care for an ICU patient with delirium is significantly higher than an ICU patient without an episode of delirium. ${ }^{10}$ It is estimated that total healthcare costs for delirium range up to $\$ 152$ billion per year in the USA. ${ }^{11}$

The duration of delirium is independently associated with long-term cognitive impairment, one aspect of post intensive care syndrome commonly experienced by critical illness survivors. ${ }^{12}$ However, management of delirium risk factors can reduce the frequency 
and duration of delirium. ${ }^{13}$ The Society of Critical Care Medicine's ABCDEF bundle was developed to reduce delirium, improve pain management and encourage early mobility, and for use of appropriate medication and family involvement to reduce long-term consequences for adult ICU patients. Component D of the ABCDEF bundle focuses on assessing, preventing and managing delirium and promotes use of the Confusion Assessment Method for the ICU (CAM-ICU) tool to monitor delirium through evaluation of mental status, inattention, altered consciousness and disorganised thinking. ${ }^{1}$ The CAM-ICU tool was developed and validated in non-verbal mechanically ventilated ICU patients but does not determine type or severity of delirium. ${ }^{3}$

The CAM-ICU tool can be challenging to implement because training is required to ensure that providers are familiar with all components of the tool and are able to interpret findings before applying the tool in clinical practice. Although the sensitivity of the CAM-ICU tool in identifying delirium has been reported at $81 \%$, education and guidance are needed to achieve this level of sensitivity. Devlin et al reported that the per cent of ICU nurses able to effectively evaluate delirium increased significantly after implementation of delirium assessment training and scripted case scenarios. ${ }^{14}$ Once staff are trained on the CAM-ICU tool, an additional challenge is ensuring that screening is performed regularly and consistently. Education and training by itself does not ensure sustainability and demands process and culture changes.

It is widely accepted that prevention is key in delirium management. At this time, treatment options are limited once a patient becomes delirious. Non-pharmacological interventions are reported to decrease the duration of delirium; however, there is not enough evidence to support pharmacological interventions, further highlighting the importance of delirium prevention and early identification. $^{11315}$

\section{BASELINE MEASUREMENT}

Delirium screening was measured in ventilated and non-ventilated ICU patients 18 years and older at an urban tertiary care hospital. Patients with traumatic brain injury, severe intellectual disability, patients receiving comfort care only and patients with a Richmond Agitation Sedation Scale score of -4 or -5 with or without sedation were excluded from the study. Documentation of delirium screening was tracked by the Electronic Health Record. Documentation by nursing staff was measured per 12 hour shift and documentation of physician communication of delirium status during rounding was measured per 24 hours. Results are displayed as a percentage with the numerator representing the number of patients with documentation at least once per 12 hour shift and the denominator representing all patients included in the audit.

In August 2015, an initial audit revealed that delirium screening using the CAM-ICU assessment tool was performed by nursing staff at least once in a 12 hour shift in $31 \%(5 / 16)$ of patients. Based on initial audit data, delirium was under-recognised and undercoded. Further investigation revealed that staff were more familiar with hyperactive delirium but were not formally trained to recognise hypoactive delirium or use the CAM-ICU assessment tool. A standardised approach was needed to improve delirium recognition, documentation and timely management of care.

\section{DESIGN}

This project was reviewed by the local institutional review board. It was determined that this project was not research involving human subjects. Lean Six Sigma methodology determined potential causes for ICU patients with undocumented and unidentified delirium. Solutions were chosen based on input from front-line providers and members of a delirium committee. Effort to implement the solutions and potential impact were considered. A standardised delirium screening tool and critical care progress note were developed in addition to education and training. Interventions were implemented between January 2016 and December 2016. Change in process was targeted to maintain sustainability. Two-proportion tests were used to determine differences in the per cent of patients with delirium screening documentation and 30-day mortality rates. Mann-Whitney U test was used to determine differences in ICU length of stay and $\chi^{2}$ analysis was used to determine differences in severity of illness, determined by All Patient Refined Diagnosis Related Groups. A p value of $<0.05$ was considered significant.

\section{STRATEGY}

\section{Plan-Do-Study-Act (PDSA) Cycle 1, Education}

ICU nurses completed simulation based education and training in January 2016 that focused on delirium assessments and sedation management. The simulation was performed at the institution's simulation centre. Nurses completed CAM-ICU video training and education in October 2016. All nurses on the medical ICU floor were trained on delirium, the ABCDEF bundle and the CAM-ICU assessment tool through three online educational videos. Nurses were required to watch the videos and were given time during work hours to complete the training. Critical Care physicians were available for individual consultations and questions.

\section{PDSA Cycle 2, Delirium Screening Documentation Changes}

The CAM-ICU assessment tool was implemented into the Electronic Health Record to standardise delirium screening in December 2016. If at any point in the delirium screening process the patient did not meet criteria, the screening tool would autopopulate the remaining steps, reducing the number of required clicks and making it easier for nursing staff to complete the assessment. Before implementation of this conditional logic strategy, nurses had to manually select options from 
a dropdown menu for each feature in the CAM-ICU tool, requiring five clicks for documenting delirium status. The new strategy allowed nurses to fill in the minimum required responses, decreasing the number of clicks for delirium documentation.

Physicians were expected to communicate daily with a multidisciplinary ICU team during rounds and develop a management strategy to prevent or treat delirium. Communication of delirium status was standardised using a critical care progress note template that included ABCDEF elements, delirium status and a management plan. Physicians reviewed delirium and were educated on the changes to the clinical care note during a Critical Care Committee meeting.

To further promote delirium documentation, the per cent of time CAM-ICU delirium assessments were documented was posted on a whiteboard in a central location in the ICU for real-time feedback to nurses and physicians.

We hypothesised that the proportion of ICU patients actively screened for delirium at least once every 12 hours would increase post-intervention compared with baseline due to educational training, participation in simulation and standardisation of the process through the CAM-ICU tool and physician progress notes.

\section{RESULTS}

Pre-intervention, delirium assessments for ICU patients were only being performed by nurses at least once in a 12 hour shift in $40 \%(12 / 30)$ of patients during the dayshift. Post simulation training and CAM-ICU education, the per cent of patients with delirium assessments at least once per 12 hour shift increased to $69 \%(41 / 59)$ (two-proportion test, $\mathrm{p}<0.01$ ). Following additional documentation changes, delirium assessments further increased to $93 \%(75 / 81)$ (two-proportion test, $\mathrm{p}<0.01)$. During the nightshift, delirium assessments were being performed by nurses $27 \%(8 / 30)$ of the time pre-intervention. After the educational training, documentation increased to $61 \%(36 / 59)$ (two-proportion test, $\mathrm{p}<0.01)$. Post documentation changes, nurses documented delirium status at least once per 12 hour shift in $71 \%$ $(56 / 79)$ of the patients (figure 1$)$.

Physicians were not required to document CAM-ICU screening before December 2016. After the standardised critical care note was implemented in December 2016, documentation by physicians averaged 95\% (106/111). Severity of illness, length of stay in the ICU and 30-day mortality rates were not altered post-intervention (table 1).

Certificates of appreciation were placed on the central board in the ICU in May 2017 to inform staff of documentation performance. As part of the Lean Six Sigma process to maintain sustainability, a control plan was developed and implemented after completion of the project. As part of the control plan, the project was handed over to the ICU nurse manager who performs quarterly audits on CAM-ICU documentation by nurses and documentation of multidisciplinary collaboration during rounding by physicians. Results are shared on the central board in the ICU. If performance decreases, a strategy is in place for provider feedback and education. Compliance with delirium screening has remained consistently high in the control phase.

\section{CAM-ICU Documentation}

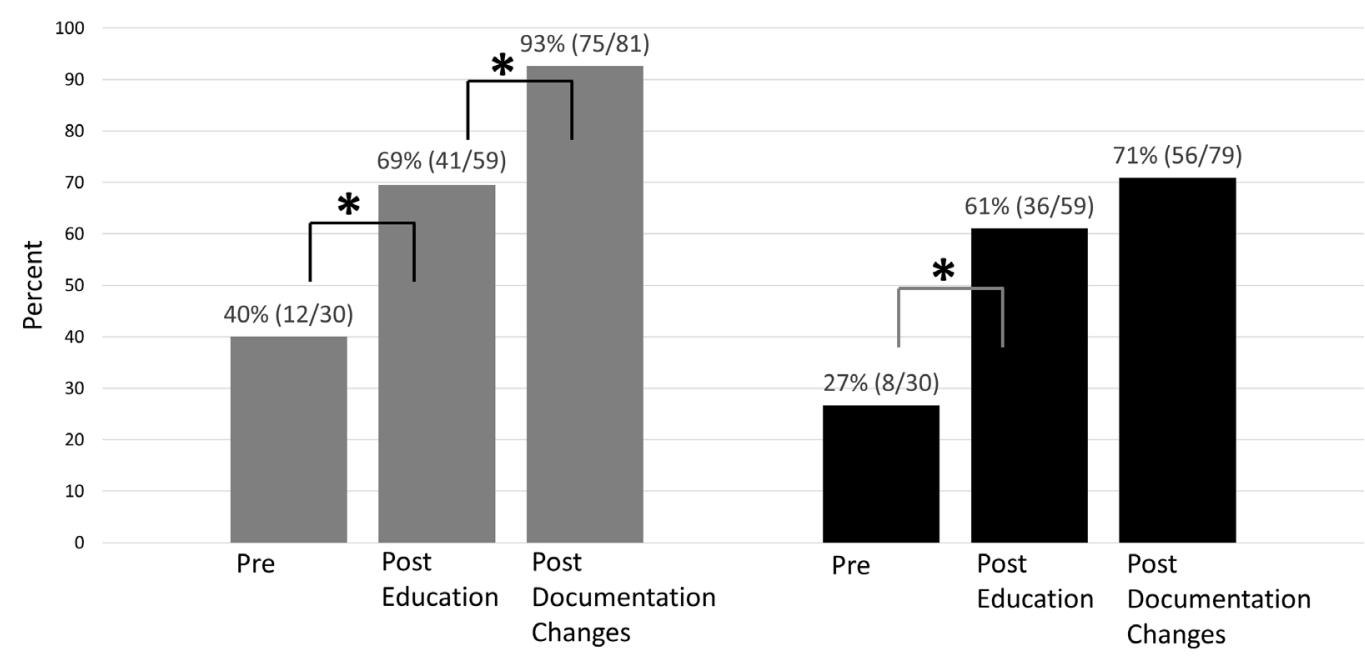

- RN Documentation (Day) - $\quad$ RN Documentation (Night)

Figure 1 The per cent of ICU patients with CAM-ICU documentation at least once per 12 hour shift was increased following education and implementation of the CAM-ICU assessment tool into the Electronic Health Record. Nursing documentation compliance was measured during both dayshift and nightshift. ${ }^{*} \mathrm{P}<0.01$. CAM-ICU, Confusion Assessment Method for the intensive care unit. 
Table 1 Severity scores, ICU length of stay and 30-day mortality rates were not significantly different pre-intervention and post-intervention

\begin{tabular}{llll}
\hline & Pre-intervention & Post-intervention & P values \\
\hline Severity 1-Minor & $8 / 393(2.04 \%)$ & $28 / 1226(2.28 \%)$ & $\chi^{2}, \mathrm{p}=0.147$ \\
Severity 2-Moderate & $41 / 393(10.43 \%)$ & $139 / 1226(11.34 \%)$ & \\
Severity 3-Major & $174 / 393(44.27 \%)$ & $453 / 1226(36.95 \%)$ & \\
Severity 4-Extreme & $159 / 393(40.46 \%)$ & $566 / 1226(46.17 \%)$ & \\
No severity listed & $11 / 393(2.80 \%)$ & $40 / 1226(3.26 \%)$ & Mann-Whitney U test, $\mathrm{p}=0.060$ \\
ICU length of stay (Median) & 2 days & 2 days & Two proportion test, $\mathrm{p}=0.938$ \\
30-day mortality & $16 / 393(4.07 \%)$ & $51 / 1226(4.16 \%)$ & \\
\hline
\end{tabular}

ICU, intensive care unit.

\section{LESSONS AND LIMITATIONS}

Although the interventions were successful in increasing delirium documentation, nurses may be over documenting on some patients. For example, CAM-ICU assessment was documented on one patient seven times within a 24-hour period. Additionally, documentation on patients that are admitted during early morning hours could be missed if a shift change occurs before the full documentation process is completed. A limitation of the study was that it was performed at a single institution and results cannot be generalised. In addition, documentation results are displayed per patient rather than continuously for every 12-hour period. We learnt that significant challenges to process change can be identified through communication with stakeholders. Finally, we believe involvement in quality improvement projects should be incorporated into residency training and required for administrative staff. Overall, multidisciplinary collaboration can result in significant positive outcomes.

\section{CONCLUSION}

Using conditional logic to autopopulate the remaining fields in the CAM-ICU documentation tool if the patient did not meet criteria made it easier for nurses to document delirium status and led to improved screening compliance. Discussion of delirium status, preventative strategies and/or treatment strategies during daily rounds with the ICU team are important in order to provide excellent patient care. The standardised clinical care note facilitated this communication and helped improve compliance. Education alone improved delirium screening but would be suboptimal to sustain increased delirium screening long term. Active involvement of senior leadership in the institution, following Lean Six Sigma methodologies and engaging frontline providers were key to the success of increasing delirium screening for ICU patients.

\section{Acknowledgements Mary Greenwalt, Kris Reichert, Brittany Gallivan.}

Contributors KA contributed to study concept and design, analysis and interpretation of data and statistical expertise. SK contributed to acquisition of the data. MM contributed to acquisition of the data and drafting of the manuscript. YS contributed to the simulation training for nurses. PW contributed to drafting of the manuscript and provided administrative and technical support. CJ contributed to drafting of the manuscript and critical revision of the manuscript. Mary Greenwalt contributed statistical expertise. All contributors reviewed the manuscript.

Funding The authors have not declared a specific grant for this research from any funding agency in the public, commercial or not-for-profit sectors.

Competing interests KA received funding from the Society of Critical Care Medicine's THRIVE Collaborative Initiative.

Patient consent Not required.

Provenance and peer review Not commissioned; externally peer reviewed.

Open access This is an open access article distributed in accordance with the Creative Commons Attribution Non Commercial (CC BY-NC 4.0) license, which permits others to distribute, remix, adapt, build upon this work non-commercially, and license their derivative works on different terms, provided the original work is properly cited, appropriate credit is given, any changes made indicated, and the use is non-commercial. See:Chttp:// creativecommons.org/licenses/by-nc/4.0/.

\section{REFERENCES}

1. Barr J, Fraser GL, Puntillo K, et al. Clinical practice guidelines for the management of pain, agitation, and delirium in adult patients in the intensive care unit. Crit Care Med 2013;41:263-306.

2. Society of Critical Care Medicine. ICU Liberation: ABCDEF bundle improvement collaborative. http://www.iculiberation.org/About/ collaborative/Pages/default

3. Ely E, Inouye S, Bernard G, et al. Delirium in mechanically ventilated patients: validity and reliability of the confusion assessment method for the intensive care unit (CAM-ICU). JAMA 2001;285:2703-10.

4. Ely EW, Shintani A, Truman B, et al. Delirium as a predictor of mortality in mechanically ventilated patients in the intensive care unit. JAMA 2004;291:1753-62.

5. Thomason JW, Shintani A, Peterson JF, et al. Intensive care unit delirium is an independent predictor of longer hospital stay: a prospective analysis of 261 non-ventilated patients. Crit Care 2005;9:R375-81.

6. Lipowski ZJ. Transient cognitive disorders (delirium, acute confusional states) in the elderly. Am J Psychiatry 1983;140:1426-36.

7. Peterson JF, Pun BT, Dittus RS, et al. Delirium and its motoric subtypes: a study of 614 critically ill patients. J Am Geriatr Soc 2006;54:479-84

8. Ouimet S, Kavanagh BP, Gottfried SB, et al. Incidence, risk factors and consequences of ICU delirium. Intensive Care Med 2007;33:66-73.

9. Lin SM, Liu CY, Wang $\mathrm{CH}$, et al. The impact of delirium on the survival of mechanically ventilated patients. Crit Care Med 2004;32:2254-9.

10. Milbrandt EB, Deppen S, Harrison PL, et al. Costs associated with delirium in mechanically ventilated patients. Crit Care Med 2004:32:955-62.

11. Leslie DL, Inouye SK. The importance of delirium: economic and societal costs. J Am Geriatr Soc 2011;59(Suppl 2):S241-S243.

12. Girard TD, Jackson JC, Pandharipande PP, et al. Delirium as a predictor of long-term cognitive impairment in survivors of critical illness. Crit Care Med 2010;38:1513-20. 
13. Inouye SK, Bogardus ST, Charpentier PA, et al. A multicomponent intervention to prevent delirium in hospitalized older patients. $N$ Engl J Med 1999;340:669-76.

14. Devlin JW, Marquis F, Riker RR, et al. Combined didactic and scenario-based education improves the ability of intensive care unit staff to recognize delirium at the bedside. Crit Care 2008;12:R19.
15. Hipp DM, Ely EW. Pharmacological and nonpharmacological management of delirium in critically ill patients. Neurotherapeutics 2012;9:158-75. 